\title{
LA RESTRICCIÓN DE LOS DERECHOS HUMANOS EN ÉPOCAS DE EMERGENCIA SANITARIA, ECONÓMICA Y SOCIAL
}

\author{
THE RESTRICTION OF HUMAN RIGHTS IN TIMES OF \\ HEALTH, ECONOMIC AND SOCIAL EMERGENCY
}

Juan Santiago Ylarri ${ }^{1}$

DOI: https://doi.org/10.37767/2591-3476(2020)20

RESUMEN:

El trabajo tiene por objeto analizar las restricciones de los derechos humanos en épocas de emergencia. En particular, se estudian los supuestos en los que es válido restringir con mayor intensidad los derechos individuales. Seguidamente, se indica si, para enfrentar esta situación, correspondía declarar el estado de sitio o bien resultaba válido dictar decretos de necesidad y urgencia. Se hace hincapié en la necesidad de respetar el diseño federal de Argentina y evitar decisiones centralizadas. Finalmente, se destaca la importancia de que el Congreso y el Poder Judicial cumplan los roles que constitucionalmente le corresponden en situaciones de emergencia.

\section{ABSTRACT}

The purpose of this paper is to analyze the restrictions of human rights in times of emergency. In particular, the cases in which it is valid to restrict individual rights with greater intensity are studied. It is specified whether, in order to face this situation, it was appropriate to declare the state of siege or it was valid to issue decrees of necessity and urgency. The need to respect Argentine federal design and avoid centralized decisions is emphasized. Finally, the importance of Congress and the Judicial Power fulfilling the roles that constitutionally correspond to it in emergency situations is highlighted.

PALABRAS CLAVE: Coronavirus, emergencia, decretos de necesidad y urgencia, poder legislativo, control judicial.

KEY WORDS: Coronavirus, emergency, decrees of need and urgency, legislative branch, judicial review.

\footnotetext{
1 Abogado y Doctor en Derecho (UBA). Máster en Derecho Constitucional (Centro de Estudios Políticos y Constitucionales, España). Especialista en Derecho Administrativo Económico (UCA). Profesor de Derecho Constitucional y Derecho Administrativo, en grado y posgrado, en UBA, UCES y UNLaM. Investigador adscripto al Instituto de Investigaciones Jurídicas y Sociales "Ambrosio L. Gioja" (UBA). Se desempeña profesionalmente en el Poder Judicial de la Nación, en el fuero Contencioso Administrativo Federal. Autor de dos libros y de más de cincuenta publicaciones sobre temas de su especialidad en revistas argentinas y extranjeras. Contacto: juan@ylarri.com.ar. https://orcid.org/0000-0001-7805-4509.

Este trabajo se enmarca en el Proyecto de Investigación del Programa de Investigación Científica, Desarrollo y Transferencia de Tecnologías e Innovaciones de la Universidad Nacional de La Matanza, que lleva por título "Los alcances de la revisión judicial de las facultades legislativas del Presidente: la interpretación restrictiva".
} 


\section{Introducción}

El Coronavirus -también llamado Covid-19 o SARS-CoV-2 - ha generado una crisis global absolutamente inédita. Nuestro país, que ya se encontraba en una situación económica endeble, no ha sido la excepción. La crisis no se limita al aspecto sanitario, sino que con ella se ha profundizado una crisis económica y social. Como señala Sagüés (2019: 14), la emergencia económica, "como el ave fénix, parece morir en cierto momento pero que pronto, o más tarde, renace de sus propias cenizas y reaparece fulgurante en el horizonte jurídico, con nuevos bríos e ingeniosos vuelos rasantes".

El propósito de este trabajo es analizar la restricción de los derechos constitucionales en épocas de emergencia. Luego de reseñar brevemente las normas aprobadas para enfrentar la pandemia, me referiré a los supuestos en los cuales es válido restringir derechos constitucionales en situaciones excepcionales. Seguidamente, indicaré si debía declararse el estado de sitio para enfrentar esta situación, o bien si resultó adecuado acudir al dictado de los decretos de necesidad y urgencia. Finalmente, haré hincapié en la necesidad de respetar el diseño federal de Argentina y evitar decisiones centralizadas, así como la importancia que el Congreso y el Poder Judicial cumplan los roles que constitucionalmente le corresponden.

\section{Las principales normas adoptadas para enfrentar el Coronavirus}

Para enfrentar los efectos del Coronavirus en Argentina, en un primer momento el Poder ejecutivo nacional dictó el decreto de necesidad y urgencia 260/20². La mencionada norma, amplió la emergencia pública en materia sanitaria establecida en la ley $27.541^{3}$, en virtud de la pandemia declarada por la Organización Mundial de la Salud (OMS) en relación con el Coronavirus por el plazo de un año a partir de la entrada en vigencia del decreto ${ }^{4}$. A su vez, otorgó numerosas facultades al Ministerio de Salud, en su carácter de autoridad de aplicación ${ }^{5}$, y dispuso que el citado ministerio conjuntamente con el Ministerio de Desarrollo Productivo podrían fijar precios máximos para el alcohol en gel, los barbijos, u otros insumos críticos, definidos como tales ${ }^{6}$. Asimismo, estableció que en determinados casos debería guardarse un aislamiento obligatorio ${ }^{7}$, y que se suspenderían los vuelos internacionales de pasajeros provenientes de determinadas "zonas afectadas", durante el plazo de treinta días ${ }^{8}$.

Ante el avance de la pandemia, se estableció la prohibición de ingreso al territorio nacional a personas extranjeras no residentes en el país, a través de cualquier punto de acceso ${ }^{9}$. Aquella prohibición se extendió luego incluso a personas residentes en el país

\footnotetext{
2 B.O. 12/3/2020. Luego modificado parcialmente por el decreto 287/20 (B.O. 18/3/2020). En virtud de este decreto, mediante la acordada 4/20 (16/3/2020), la Corte Suprema declaró inhábiles los días 16 a 31 de marzo de 2020 para las actuaciones judiciales ante todos los tribunales que integren el Poder Judicial de la Nación. Al mismo tiempo, dispuso que los tribunales aseguren una prestación mínima de servicio de justicia.

3 B.O. 23/12/2019, ley denominada de Solidaridad Social y Reactivación Productiva.

4 Art. $1^{\circ}$.

5 Art. $2^{\circ}$.

6 Art. $6^{\circ}$. Ver al respecto la Resolución Conjunta 1/2020 (B.O. 21/3/2020) que luego de establecer los insumos críticos sanitarios necesarios para mitigar la propagación del Coronavirus intimó a las empresas productoras, distribuidoras y comercializadoras que participen de la cadena de producción de dichos insumos a incrementar la producción, distribución y comercialización de dichos insumos hasta el máximo de su capacidad instalada, y arbitrar los medios para asegurar su distribución y provisión a la población y entidades de salud.

También, cabe señalar que el decreto 287/20, incorporó al decreto $260 / 20$ el art. 15 bis, que suspendió por el plazo que dure la emergencia, el último párrafo del artículo $1^{\circ}$ de la ley de abastecimiento 20.680 (B.O. 25/6/1974), que exceptuaba de dicho régimen a los agentes económicos considerados micro, pequeñas o medianas empresas.

7 Art. $7^{\circ}$.

8 Art. $9^{\circ}$.

9 Decreto 274/20 (B.O. 16/3/2020). La norma fue prorrogada por los decretos 331/20 (B.O. 1/4/2020), 365/20 (B.O. 11/4/2020) y 409/20 (B.O. 26/4/2020).
} 
y a los nacionales con residencia en el exterior ${ }^{10}$. En la misma línea, a finales del mes de abril, mediante una resolución de la Administración Nacional de Aviación Civil se estableció que las líneas aéreas que operan servicios de transporte aéreo de pasajeros desde, hacia o dentro del territorio nacional, podrían comercializar pasajes aéreos con fecha de inicio de operaciones a partir del 1/9/202011. Esto implica prácticamente la imposibilidad de salir del territorio o que quienes se encuentren fuera no puedan ingresar.

Por su parte, el decreto de necesidad y urgencia 297/2012, estableció para todas las personas que habitan en el país o que se encuentren en él en forma temporaria, la medida de "aislamiento social, preventivo y obligatorio", con vigencia desde el 20 hasta el 31 de marzo, pudiéndose prorrogar este plazo por el tiempo que se considere necesario en atención a la situación epidemiológica ${ }^{13}$. Ante el incumplimiento del aislamiento, la norma prevé que debe procederse de inmediato a hacer cesar la conducta infractora y dar actuación a la autoridad competente, en el marco de los arts. 205, 239 y concordantes del Código Penal14.

De este modo, se dispuso que durante la vigencia del "aislamiento social, preventivo y obligatorio" no podrían realizarse eventos culturales, recreativos, deportivos, religiosos, ni de ninguna otra índole que impliquen la concurrencia de personas. A su vez, se suspendió la apertura de locales, centros comerciales, establecimientos mayoristas y minoristas, y cualquier otro lugar que requiera la presencia de personas ${ }^{15}$.

Por supuesto, la norma fijó una serie de excepciones. Así, estableció que quedaban exceptuadas del cumplimiento del aislamiento y de la prohibición de circular, las personas afectadas a las actividades y servicios declarados esenciales en la emergencia que la norma detalla, poniendo de relieve que los desplazamientos debían limitarse al estricto cumplimiento de esas actividades y servicios ${ }^{16}$.

La implementación y el combate frente al Coronavirus conllevan un esfuerzo federal. Así, el decreto dispuso que las provincias, la Ciudad Autónoma de Buenos Aires y los municipios debían dictar las medidas necesarias para implementar lo dispuesto en él,

\footnotetext{
10 Decreto $313 / 20$ (B.O. 27/3/2020).

11 Resolución 133/20 (B.O. 27/4/2020).
}

12 B.O. 18/3/2020. El aislamiento fue prorrogado por los decretos 325/20 (B.O. 31/3/2020), 355/20 (B.O. 11/4/2020), 408/20 (B.O. 26/4/2020), 459/20 (11/5/2020), 493/20 (B.O. 25/5/2020), 520/20 (B.O. 8/6/2020) y 576/20 (B.O. 29/6/2020). Este último, dispuso también el "distanciamiento social, preventivo y obligatorio" para todas las personas que residan o transiten en aglomerados urbanos, partidos y departamentos de las provincias argentinas que posean ciertos parámetros epidemiológicos y sanitarios.

En la misma línea, la Corte Suprema mediante acordada 6/20 (B.O. 26/3/2020) dispuso feria extraordinaria respecto de todos los tribunales federales y nacionales y demás dependencias que integran este Poder Judicial de la Nación, desde el 20 hasta el 31 de marzo de 2020, indicando que la misma se extendería por igual plazo que el que Poder Ejecutivo Nacional pudiera disponer su prórroga. La feria extraordinaria fue prorrogada por las acordadas $8 / 20$, $10 / 20,13 / 20,14 / 20,16 / 20,18 / 20$ y 25/20. Las acordadas $12 / 20$ y 14/20 permitieron que los distintos tribunales nacionales federales que tengan a su cargo la superintendencia de cada fuero jurisdicción puedan ampliar las materias a ser consideradas por aquellos tribunales durante la feria extraordinaria. A su vez, la acordada 14/20 aprobó el "Protocolo y pautas para la tramitación de causas judiciales durante la feria extraordinaria", el "Protocolo referido a la convocatoria de funcionarios y empleados", el "Protocolo para formular consultas en el Poder Judicial" y el "Protocolo de medidas de prevención, higiene y seguridad para el Poder Judicial de la Nación por la pandemia de Covid-19”. Asimismo, mediante las acordadas 17/20, 19/20, 20/20 y 23 en ciertas jurisdicciones se dispuso el levantamiento de la feria judicial.

13 Art. $1^{\circ}$

14 Art. $4^{\circ}$. El art. 205 del Código Penal dispone lo siguiente: "Será reprimido con prisión de seis meses a dos años, el que violare las medidas adoptadas por las autoridades competentes, para impedir la introducción o propagación de una epidemia”. Por su parte, el art. 239 determina: "Será reprimido con prisión de quince días a un año, el que resistiere o desobedeciere a un funcionario público en el ejercicio legítimo de sus funciones o a la persona que le prestare asistencia a requerimiento de aquél o en virtud de una obligación legal".

15 Art. $5^{\circ}$

16 Art. $6^{\circ}$. La norma permitió que el Jefe de Gabinete de Ministros, en su carácter de coordinador de la "Unidad de Coordinación General del Plan Integral para la Prevención de Eventos de Salud Pública de Importancia Internacional” y con recomendación de la autoridad sanitaria podría ampliar o reducir las excepciones dispuestas. 
como delegados del gobierno federal, conforme lo establece el art. 128 de la Constitución Nacional, sin perjuicio de otras medidas que deban adoptar tanto las provincias, como la Ciudad Autónoma de Buenos Aires, como los municipios, en ejercicio de sus competencias propias ${ }^{17}$.

Estas normas fueron complementadas por otros decretos, decisiones administrativas, resoluciones y disposiciones de diversos organismos, como las que dispusieron la abstención del corte de servicios en caso de mora o falta de pago ${ }^{18}$, la suspensión de cierre de cuentas bancarias por determinado plazo por librar cheques sin fondos ${ }^{19}$, el congelamiento del valor de las cuotas de créditos hipotecarios y la suspensión de las ejecuciones hipotecarias ${ }^{20}$, la suspensión de desalojos, la prórroga de los contratos de locación y congelamiento del precio de alquilere ${ }^{21}$, la suspensión del deber de asistencia al lugar de trabajo con goce íntegro de las remuneraciones ${ }^{22}$, la prohibición de los despidos sin justa causa y por las causales de falta o disminución de trabajo y fuerza mayor, así como las suspensiones por dichos motivos ${ }^{23}$, la suspensión del dictado de clases presenciales en los niveles inicial, primario, secundario en todas sus modalidades, e institutos de educación superior ${ }^{24}$. También se dictaron normas con incidencia en el procedimiento administrativo, como las que dispusieron la suspensión de los plazos ${ }^{25}$ y la admisión de efectuar contrataciones directas en la administración pública ${ }^{26}$. A su vez, se modificó el Presupuesto General de la Administración Nacional para el ejercicio 2020 y se suspendió durante el mismo ejercicio, para aquellas modificaciones presupuestarias necesarias en virtud de medidas dictadas en el marco de las disposiciones del decreto 260/20, la aplicación de los límites a las reestructuraciones presupuestarias que puede disponer el Jefe de Gabinete de Ministros establecidos en la ley de Administración Financiera y de los Sistemas de Control del Sector Público Nacional ${ }^{27}$.

Se ha puesto de relieve también que, para enfrentar la pandemia, los gobiernos realizan "vigilancia digital", que incluye el control mediante las cámaras de televisión, de los celulares, drones, big data y la inteligencia artificial, permiten tener información sobre los movimientos de cada individuo (Lorenzetti, 2020a, 2020b).

\section{La restricción más intensa de derechos constitucionales en épocas de emergencia}

La pandemia generará una serie de cambios a nivel mundial en todo tipo de órdenes. En efecto, Snowden (2019: 2-7) -quien, pocos meses antes de la crisis generada por el coronavirus expresó que la sociedad moderna es extremadamente vulnerable al desafío de una pandemia- señala que las enfermedades infecciosas son tan importantes para comprender el desarrollo social como las crisis económicas, las guerras, las revoluciones y el cambio demográfico. En este sentido, refiere que las epidemias han impactado no

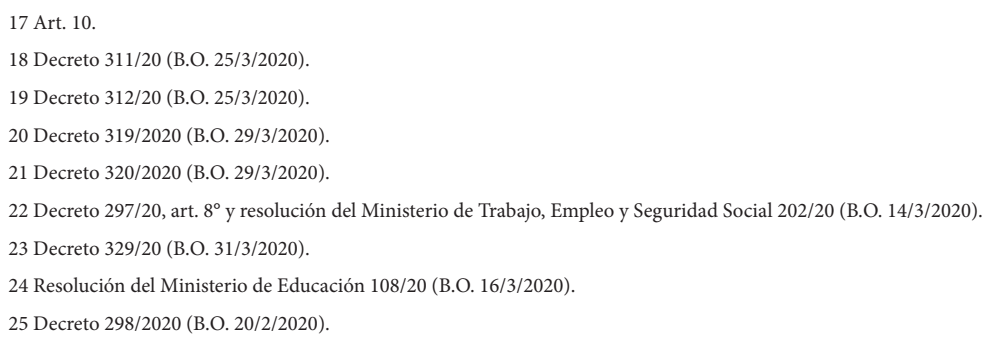

26 Art. 15 ter del decreto 260/20, incorporado por el decreto 287/20. Ver al respecto la Decisión administrativa 409/2020 (B.O. 18/3/2020) y la disposición de la Oficina Nacional de Contrataciones 48/20 (B.O. 20/3/2020).

27 Decreto $427 / 20$ (B.O. 11/5/2020). 
sólo en la vida de las personas, sino también en la religión, las artes, el surgimiento de la medicina moderna y la salud pública, y la historia de las ideas.

La crisis del Coronavirus ha producido que la totalidad de las relaciones jurídicas se vea impactada por la acción estatal a escala global. Las nociones de propiedad, comercio y contrato, las relaciones interpersonales, y aun las de familia, se ponen en cuestionamiento (Vítolo, 2020). Así, la pandemia ha generado una gran restricción de derechos, incluso en las relaciones privadas (Mazzinghi, 2020). Esta crisis se da también en un contexto económico crítico de la economía Argentina, por lo que es esperable que se dicten nuevas medidas en este sentido, con sustento en la doctrina de emergencia (Schurig, 2020).

Ahora bien, para analizar el marco en el cual fueron dictadas las normas mencionadas, cabe distinguir en el derecho constitucional las situaciones de normalidad y las situaciones de excepción. En efecto, como lo ha destacado el jurista español Cruz Villalón (1984: 17-19), la Constitución configura un determinado proyecto en relación con una situación considerada normal y previsible. Sin embargo, aquella norma puede verse súbitamente confrontada con una situación distinta, no prevista, por lo que la Constitución puede encontrarse en una situación de no poder asegurar su propia eficacia. Frente a estas situaciones, las Constituciones incorporan a su ordenamiento un modo alternativo de organización del poder que supone la negación temporal del orden constitucional en principio previsto, pero la cual tiene al menos dos ventajas. Por un lado, mantiene la eficacia formal de la Constitución como Constitución "alternativa" de emergencia, evitando la imposición de la fuerza normativa de lo fáctico. Por otro lado, facilita la vuelta ordenada a la Constitución ordinaria o "legítima".

Así las cosas, hay que distinguir los "eventos o situaciones de emergencia" y los "institutos de emergencia". Los primeros, son acontecimientos reales o fácticos, eventos que perturban el orden constitucional con carácter de emergencia. En cambio, los institutos de emergencia, son creaciones del derecho que importan medidas de prevención, seguridad y remedio para contener, atenuar o subsanar las emergencias (Bidart Campos, 1995: 301). En lo que respecta a las prescripciones constitucionales con relación a los institutos de emergencia, cabe señalar que si bien la gama de emergencias es muy variada ${ }^{28}$, la Constitución, hasta la reforma de 1994, siempre reguló uno sólo: el estado de sitio, aplicable a las emergencias de la guerra (ataque exterior) y a la conmoción interior, en su art. 23. A su vez, otros autores, sostienen que puede incluirse dentro de los institutos de emergencia a la intervención federal, prevista en el art. 6 de la Constitución, que procede para garantizar la forma republicana de gobierno, o repeler invasiones exteriores, y a requisición de sus autoridades constituidas para sostenerlas o restablecerlas, si hubiesen sido depuestas por la sedición, o por invasión de otra provincia (Dalla Vía, 2002: 40-41). En la misma línea, Gelli (2008: t. I, 390) sostiene que el estado de sitio, junto con la intervención federal, constituyen las respuestas institucionales, regladas por la Constitución nacional, ante emergencias de carácter político. Afirma, a su vez, que luego de la reforma de 1994 se admitieron dos tipos más de emergencias, las que dan lugar a la delegación legislativa y las que autorizan el dictado de decretos de necesidad y urgencia. Así podríamos decir que hay cuatro institutos de excepciones. Dos existentes desde la Constitución de 1853/60, la intervención federal y el estado de sitio; y dos incorporados

28 Sin perjuicio de los institutos de excepción que más adelante se abordarán, Sacristán (2014) enumera diversos institutos que integran las "medidas de emergencia”, entre los que menciona el estado de asamblea, la ley marcial, las facultades extraordinarias o suma del poder público, el estado de prevención y de alarma, el estado de guerra interno, y la revolución. 
en la reforma constitucional de 1994, la delegación legislativa y los decretos de necesidad y urgencia, aunque ya habían sido admitidos con anterioridad por la jurisprudencia de la Corte Suprema.

A su vez, en lo que respecta a las características que poseen los institutos de emergencia, se distinguen dos características fundamentales. Por un lado, acrecientan ciertas competencias del poder, reforzando algún órgano de gobierno. Por el otro, originan una restricción a las libertades, derechos y garantías individuales (Bidart Campos 1995: 301; Padilla, 2002; Loianno, 2005; Gross y Ní Aoláin, 2006; Jakab, 2006; Diana, 2020). Esto es precisamente lo que ocurre en esta emergencia sanitaria, en la cual el Poder Ejecutivo ha reforzado su poder, dictando numerosas normas y delegando también facultades en diversos organismos de la Administración Pública. A su vez, se han restringido numerosos derechos constitucionales. Pensemos que con la adopción de estas normas no se pueden realizar actividades tan elementales como transitar por la calle, abrir las puertas de un comercio, ir al colegio, asistir a un recital, un partido de fútbol o a una ceremonia religiosa, o salir a correr por un parque, cuestiones que las normas comentadas vedan.

Así, en el centro de la cuestión se encuentra el art. 19 de la Constitución nacional, según el cual "las acciones privadas de los hombres que de ningún modo ofendan al orden y a la moral pública, ni perjudiquen a un tercero, están sólo reservadas a Dios, y exentas de la autoridad de los magistrados". De este modo, en la medida que exista el riesgo razonable que una persona pueda contagiar el nuevo Coronavirus, su accionar deja de ser privada, y se admite la intervención estatal.

Ahora bien, cabe señalar que aun en tiempos normales los derechos reconocidos constitucionalmente no son absolutos, sino que están sujetos a las leyes que reglamenten su ejercicio ${ }^{29}$, siempre que aquella reglamentación sea razonable ${ }^{30}$. Así, se ha definido al poder de policía como la facultad del Estado de limitar el ejercicio de los derechos individuales para asegurar determinadas finalidades con el consiguiente efecto de limitar los derechos individuales para hacer efectivos esos objetivos concretos. Se distingue un concepto restringido ("narrow") de poder de policía, de origen europeo, que comprende la seguridad, salubridad o moralidad y un concepto amplio ("broad") de origen norteamericano, que agrega el bienestar general (Hernández, 2004: 358). La Corte Suprema en sus comienzos ya definió el poder de policía ${ }^{31}$. Sobre el poder de policía restringido, en el precedente "Plaza de Toros" el máximo tribunal sostuvo que "es un hecho y también un principio de derecho constitucional, que la policía de las provincias está a cargo de sus gobiernos locales, entendiéndose incluido en los poderes que se han reservado el de proveer lo conveniente a la seguridad, salubridad y moralidad de sus vecinos; y que, por consiguiente, pueden lícitamente dictar leyes y reglamentos con estos fines, no habiéndose garantido por el art. 14 de la Constitución nacional a los habitantes de la República el derecho absoluto de ejercer su industria o profesión, sino con sujeción a las leyes que reglamentan su ejercicio"32. Un precedente que ha vuelto a tener una gran actualidad es

\footnotetext{
29 Art. 14 CN: “Todos los habitantes de la Nación gozan de los siguientes derechos conforme a las leyes que reglamenten su ejercicio...”. Por su parte, el art. 99, inc. $2 \mathrm{CN}$ establece que el Presidente "Expide las instrucciones y reglamentos que sean necesarios para la ejecución de las leyes de la Nación, cuidando de no alterar su espíritu con excepciones reglamentarias".

30 Art. $28 \mathrm{CN}$ : "Los principios, garantías y derechos reconocidos en los anteriores artículos, no podrán ser alterados por las leyes que reglamenten su ejercicio".

31 CSJN, "Varios Puesteros Próximos al Mercado del Centro c/ El empresario del mismo mercado, el Dr. García Juan Agustín por varios puesteros c/ concesionarios del 'Mercado' Independencia”, 8/11/1866, Fallos: 3:468.

32 CSJN, “La Empresa 'Plaza de Toros', quejándose por un decreto expedido por el Gobierno de Buenos Aires”, 13/4/1869, Fallos: 7:150.
} 
el precedente "Saladeristas", por el cual la Corte Suprema convalidó la suspensión dispuesta por la legislatura de la provincia de Buenos Aires de las faenas de los saladeros situados en el Riachuelo de Barracas, pues eran "una amenaza constante a la salud pública en las condiciones en que se les explotaba". De este modo, adujo que no podía señalarse que se violaba el derecho de propiedad y el ejercicio de una industria lícita, pues según la Constitución, esos derechos estaban sujetos a las leyes que reglamentan su ejercicio, y que nadie tenía el derecho de propiedad, para usar de ésta en daño de otro ${ }^{33}$.

Con posterioridad, en el precedente "Russo", la Corte Suprema admitió el poder de policía de emergencia, el cual supone como presupuesto de hecho, "una situación de emergencia, es decir, la existencia de una crisis o bien de un grave trastorno social originado por acontecimientos físicos, políticos, económicos, etc. Ante la imperiosa necesidad de afrontar los daños o riesgos creados por esa situación de emergencia y de borrar o mitigar sus efectos, la potestad reglamentaria del Congreso, a la que se refiere el art. 14, se hace más amplia y profunda y, por lógica derivación, da origen a una mayor injerencia del Estado en el régimen de los derechos humanos. Operase, pues, una intensificación del poder estatal y resultan constitucionalmente válidos medios o procedimientos que en circunstancias normales no lo serían. No se trata de que la emergencia cree un nuevo poder; simplemente autoriza a ejercer con mayor energía un poder ya existente. Acontecimientos extraordinarios, ha dicho esta Corte, demandan remedios también extraordinarios. Y es indispensable que así sea, por cuanto si estos últimos no se adoptaran no sólo habría interés público insatisfecho, como ocurre cada vez que el poder de policía es usado de modo ineficiente, sino que además existiría una comunidad grave y hondamente perturbada, lo que podría comportar uno de los más graves peligros a que está expuesto el Estado democrático: el de su fracaso como custodio de la paz social y del bienestar colectivo"34.

Así las cosas, como lo ha señalado el máximo tribunal en numerosos pronunciamientos, el poder de policía de emergencia no nace fuera de la Constitución Nacional sino dentro de ella ${ }^{35}$, por lo que en determinados casos es posible el ejercicio del poder del Estado en forma más enérgica que la admisible en períodos de sosiego y normalidad ${ }^{36}$, ya que acontecimientos extraordinarios justifican remedios extraordinarios ${ }^{37}$.

Sin embargo, como bien ha señalado Marienhoff (2010: 1605-1607), el poder de policía en modo alguno constituye una potestad estatal absoluta o ilimitada, toda vez que aquello contrariaría los postulados del Estado de Derecho. Por el contrario, el autor afirma que cuando se reglamenta un derecho de índole constitucional se debe supeditar el ejercicio de ese derecho a un criterio razonable, pero que en modo alguno significa cercenar o "suprimir" el ejercicio del derecho respectivo. Por lo tanto, el hecho de que se reconozca un poder de policía amplio no implica que su ejercicio sea ilimitado, ya que incluso en el amplio sistema americano ("broad and plenary") dicho poder "tiene por fronteras los derechos constitucionales del individuo".

\footnotetext{
33 CSJN, "Los Saladeristas Podestá, Bertram, Anderson, Ferrer y otros contra la provincia de Buenos Aires; sobre indemnización de daños y perjuicios", 14/5/1887, Fallos 31:273

34 CSJN, "Russo, Angel y otra c/ C. de Delle Donne E.", 15/5/1959, Fallos: 243:467, voto de los doctores Araoz de Lamadrid y Oyhanarte, considerando 4. 35 CSJN, "Rinaldi, Francisco Augusto y otro c/ Guzman Toledo, Ronal Constante y otra s/ Ejecución hipotecaria”, 15/3/2007, Fallos: 330:855. 36 CSJN, “Vicente Martini e Hijos, S.R.L Infac. Ley 12.591”, 27/12/1944, Fallos: 200:450.

37 CSJN, “Juan Domingo Perón", 21/6/1957, Fallos: 238:76.
} 
Ahora bien, ¿cuáles son las pautas que aseguran la validez de estas normas de emergencia? Las condiciones mínimas de validez constitucional que han de reunir los institutos y medidas de emergencia pueden resumirse en las siguientes: a) la efectiva existencia de una situación de emergencia declarada por órgano competente; b) una finalidad de interés social y público; c) la transitoriedad de la regulación excepcional, es decir, sujeta a un plazo; d) la razonabilidad del medio elegido, o sea proporción y adecuación entre la medida dispuesta, el fin perseguido, y los motivos y causas que dan origen a la medida de emergencia (Bidart Campos, 2000:352) ${ }^{38}$. El control sobre el cumplimiento de estos requisitos le compete al Poder Judicial, a fin de que pueda asegurar la vigencia de los derechos y el respeto a la supremacía constitucional.

\section{Estado de sitio o decretos de necesidad y urgencia}

Habiendo afirmado la facultad del Estado de dictar normas de excepción ante circunstancias excepcionales, cabe referirse expresamente al medio escogido para declarar la emergencia sanitaria en Argentina, es decir, un decreto de necesidad y urgencia. En efecto, algunos autores se han expresado en el sentido que el Poder Ejecutivo debería haber declarado el estado de sitio (Ramírez Calvo, 2020), mientras otros se han expresado en contra de esa posibilidad (Boico, 2020; Cao, 2020). Sin perjuicio de lo expuesto, se ha apuntado que estamos frente a un "estado de sitio virtual", en tanto se han restringido prácticamente todos los derechos constitucionales, desde el derecho a trabajar hasta el derecho de ejercer libremente el culto (Ibarlucía, 2020).

El art. 23 de la Constitución nacional dispone que "[e]n caso de conmoción interior o de ataque exterior que pongan en peligro el ejercicio de esta Constitución y de las autoridades creadas por ella, se declarará en estado de sitio la provincia o territorio en donde exista la perturbación del orden, quedando suspensas allí las garantías constitucionales. Pero durante esta suspensión no podrá el presidente de la República condenar por sí ni aplicar penas. Su poder se limitará en tal caso respecto de las personas, a arrestarlas o trasladarlas de un punto a otro de la Nación, si ellas no prefiriesen salir fuera del territorio argentino".

Habría que determinar si esta crisis sanitaria quedaría comprendida dentro del supuesto de "conmoción interior". Debe tenerse presente que no basta sólo esta circunstancia, sino que esta situación debe, por un lado, poner en peligro el ejercicio de la Constitución y de las autoridades creadas por ella y, por el otro, debe existir perturbación del orden. Considero que, al menos en las actuales circunstancias en las que se encuentra el país, es dudoso que se reúnan todos estos requisitos en el caso de la pandemia del Covid-19, más aún cuando, si nos atenemos a la literalidad del texto constitucional, la norma señala que el poder del Presidente respecto de las personas se limita a "arrestarlas o trasladarlas de un punto a otro de la Nación...".

Es cierto que otros países, como España, han acudido a otros institutos de excepción y no al dictado de decretos de necesidad y urgencia. Sin embargo, cabe señalar que en aquel país no se acudió al dictado de un decreto-ley, sino que se declaró el estado de alarma, previsto en el art. 116.2 de la Constitución Española el cual está previsto, entre otros supuestos, expresamente para "crisis sanitarias, tales como epidemias y situaciones de contaminación graves" ${ }^{\prime \prime}$.

38 En sentido coincidente con las pautas enunciadas en relación con la emergencia económica por la Corte Suprema, en el precedente "Avico, Oscar Agustín c/ de la Pesa, Saúl G., 7/12/1934, Fallos: 172:21, reiteradas de forma constante por la Corte Suprema hasta la actualidad.

39 La doctrina española ha señalado que a diferencia de los estados de excepción, de alarma y de sitio, el presupuesto habilitante para los decretos-leyes es 
De este modo, teniendo en cuenta los distintos institutos de excepción contemplados en la Constitución, creo que es admisible que se utilice un decreto de necesidad y urgencia para combatir una emergencia como la suscitada por el Covid-19. Nótese la amplitud con que está redactado el texto constitucional al admitir este tipo de decretos: "Solamente cuando circunstancias excepcionales hicieran imposible seguir los trámites ordinarios previstos por esta Constitución para la sanción de las leyes (...) podrá dictar decretos por razones de necesidad y urgencia". Además, el término "conmoción interior" no es tan específico como, por ejemplo, las disposiciones previstas en el art. 116.2 de la Constitución española para el estado de alarma. Por ende, creo que no podría impugnarse la norma comentada por no ser el instrumento apto para combatir la pandemia.

\section{V. ¿Puede ampliarse una emergencia pública declarada por el Congreso a través de un decreto de necesidad y urgencia?}

En primer lugar, cabe expresarse respecto de las facultades que invocaron los decretos de necesidad y urgencia para su dictado. En ambos se expresó que la medida "se dicta en uso de las atribuciones conferidas por el artículo 99, incisos 1 y 3 de la Constitución Nacional", es decir como decretos autónomos, y como decretos de necesidad y urgencia. Si bien resulta evidente que ambos tipos de decretos no se identifican, se podría justificar la mención del art. 99, inc. $1^{\circ}$ en que hay ciertas prescripciones del decreto que son propias del Presidente.

Sin embargo, cabe destacar que el decreto 260/20, en su art. $1^{\circ}$, amplía "la emergencia pública en materia sanitaria establecida por Ley $N^{\circ} 27.541^{\prime 40}$. Como señalé antes, la reforma constitucional introdujo dos institutos de excepción nuevos. Por un lado, la posibilidad que el Congreso declare una "emergencia pública" y delegue determinadas facultades al Poder Ejecutivo, o bien que el Poder Ejecutivo, sin intervención previa del Congreso, dicte un decreto con fuerza de ley. Pero lo que no puede hacer el Presidente es ampliar una "emergencia pública", pues precisamente es al Congreso a quien le corresponde declarar las características de la "emergencia pública" y delegar dentro de determinadas bases y dentro de un plazo facultades al Poder Ejecutivo. El Presidente no podría "auto-delegarse" funciones legislativas. Considero que la ampliación dispuesta constituye un exceso de facultades. Es cierto que la ley 27.541 declaró la emergencia "sanitaria", pero aquella emergencia nada tiene que ver con la crisis generada por el Covid-19. En efecto, la doctrina ha precisado que cuando el art. 76 de la Constitución utiliza el término "determinadas" está usado en la acepción de "precisadas", por lo que el artículo prohíbe una delegación legislativa sobre una materia genérica o ambigua (Gelli, 2008: t. II, 269). Por lo tanto, al tratarse de una emergencia sanitaria distinta, el Ejecutivo se encontraba facultado para dictar un decreto de necesidad y urgencia, pero no para ampliar una emergencia pública en el marco de una delegación, pues el Poder Legislativo es el único que puede fijar las materias -especificadas en la Constitución- sobre las cuales quiere delegar determinadas facultades al Ejecutivo.

\footnotetext{
una "anormalidad de tono menor" (De Otto, 1988: 197). Sobre los diversos estados de excepción en España y su relación con el presupuesto habilitante de los decretos-leyes, ver Ylarri, 2019a: 59.

40 A modo de ejemplo, cabe mencionar que en los considerandos del decreto 319/20 se indica que la norma "se dicta en el marco de la emergencia pública en materia económica, financiera, fiscal, administrativa, previsional, tarifaria, energética, sanitaria y social establecida por la Ley $\mathrm{N}^{\circ} 27.541$, la ampliación de la emergencia sanitaria dispuesta por el Decreto $N^{\circ} 260 / 20$ y su modificatorio...". A su vez, en los considerandos del decreto $320 / 20$ se sostiene que "por el Decreto $\mathrm{N}^{\circ} 260$ del 12 de marzo de 2020 se amplió en nuestro país la emergencia pública en materia sanitaria establecida por la Ley $\mathrm{N}^{\circ} 27.541$, por el plazo de UN (1) año, en virtud de la pandemia declarada".
} 


\section{Cooperación internacional, regional y federal}

El esfuerzo para salir de esta crisis requiere de cooperación internacional. Al respecto, la Corte Interamericana, en la Declaración 1/20 ha expresado que los problemas y desafíos extraordinarios que ocasiona la presente pandemia deben ser abordados a través del diálogo y la cooperación internacional y regional conjunta, solidaria y transparente entre todos los Estados. Resaltó que el multilateralismo es esencial para coordinar los esfuerzos regionales para contener la pandemia.

En la misma línea, ante esta situación extraordinaria, la doctrina se ha planteado la necesidad de adoptar soluciones globales, políticas, planes, instituciones y normativas de carácter supranacional (Cafferata, 2020). Así, la crisis ha movilizado a distintos organismos a nivel internacional para procurar combatir la pandemia (Medina, G. y Yuba, G., 2020). Desde la misma óptica, y teniendo en cuenta nuestra forma federal de Estado, se ha puesto de manifiesto la necesidad de que los cuatro niveles de gobierno -federal, provincias, Ciudad de Buenos Aires y municipios- tengan el mejor funcionamiento posible, pues todos tienen competencia en materia de salud (Hernández, 2020a: 24). Por lo tanto, se ha sostenido que esta emergencia no puede llevar a convertirnos en un estado unitario, donde cesen las autonomías de las Provincias, la Ciudad de Buenos Aires y los municipios. En efecto, más allá del cumplimiento de los decretos 260/20 y 297/20, deben ejercitarse adecuadas relaciones interjurisdiccionales entre los diversos Gobiernos, que integran el Estado Federal (Hernández, 2020b).

Así las cosas, en cuanto al poder de policía concurrente en materia de emergencia sanitaria, se ha precisado que los municipios pueden ser más severos en tanto no interfieran sobre el interés nacional (Machiaro, 2020). Sin embargo, respecto de la aplicación de la ley de abastecimiento, la doctrina ha puesto de manifiesto los límites a la intervención de los municipios. Sobre la cuestión, Castro Videla y Maqueda (2020) sostienen que los destinatarios de las facultades de regulación, fiscalización y sanción en el régimen de la ley de abastecimiento deberían ser exclusivamente entes u órganos de la jurisdicción "provincial" o "nacional", según corresponda, sin que puedan transferirse al nivel municipal.

Por otro lado, de más está decir que aquellas disposiciones de los entes locales no deben violar la Constitución. En este sentido, cabe mencionar una resolución conjunta de la Ciudad de Buenos Aires que dispuso que las personas de setenta años o más debían comunicarse previamente con el servicio de atención ciudadana a los efectos de garantizar el conocimiento de todas las alternativas puestas a disposición por parte de la Ciudad, para evitar que aquellas personas salgan innecesariamente de su domicilio. La mencionada norma fue declarada inconstitucional por el Poder Judicial, en el entendimiento que violaba el derecho a la igualdad ${ }^{41}$. Más allá de ello, acertadamente la doctrina ha apuntado que medidas de esa índole deben formularse, como principio, por norma con rango y naturaleza de ley, nunca por resolución ministerial (Sagüés, 2020).

\section{El rol del Congreso en la emergencia}

Una cuestión sumamente relevante en esta crisis sanitaria es la ausencia prolongada del Poder Legislativo ${ }^{42}$. Al respecto, la doctrina ha puesto de relieve que la falta de funcionamiento del Congreso, constituye una cuestión de gravedad institucional que agrava

\footnotetext{
41 Juzgado de Primera Instancia en lo Contencioso Administrativo y Tributario de la Ciudad de Buenos Aires N 14, "Lanzieri, Silvano c/ GCBA s/ Amparo - Otros", Causa No 3045/2020-0, 20/4/2020.

42 Téngase presente que ambas Cámaras del Congreso retomaron sus respectivas sesiones, desde el comienzo de la crisis sanitaria, el 13 de mayo.
} 
hondamente la realización de la democracia republicana y federal. Acertadamente se ha señalado que frente a la complejidad de la pandemia, con sus múltiples problemas no sólo sanitarios, sino también políticos, económicos, sociales, institucionales, éticos e internacionales, no se puede prescindir del necesario debate y deliberación del órgano que representa la legitimidad popular en su más amplia expresión. Así, se ha indicado que la unión nacional que se necesita frente a tan grave desafío no debe implicar un pensamiento único y centralista, sino la expresión plural de la sociedad abierta, para alcanzar el mayor consenso democrático posible en la emergencia. Por el contrario, resulta fundamental que sesione el Congreso, que con sus dos Cámaras, representa al pueblo de la Nación y de las Provincias (Hernández, 2020b).

En esta línea, se ha sostenido que aunque los Poderes Ejecutivos sean los órganos que en la instancia tengan mayores competencias para afrontar la situación excepcional, ello no significa que el Congreso y los otros cuerpos legislativos dejen de cumplir sus roles para la aprobación y control de las medidas basadas en los institutos de emergencia utilizados (Hernández, 2020a: 24). En la misma línea, Sabsay (2020) señala que no se justifica que el Presidente continúe tomando decisiones de altísima importancia institucional, pues tienen que ver con la organización del Estado, con su régimen económico con efectos directos sobre los derechos de las personas, por defecto del Legislativo.

Sobre el rol del Congreso en esta emergencia, no puedo dejar de referirme a la consulta realizada por la Presidencia del Senado a la Corte Suprema. Cristina Fernández, en su carácter de Presidenta del Honorable Senado de la Nación, promovió una acción declarativa de certeza a fin de que se despeje el estado de incertidumbre respecto a la validez legal de sesionar mediante medios virtuales o remotos en el contexto de la emergencia sanitaria ocasionada por el Covid-19. Solicitó que la petición se examinara a la luz de la doctrina de gravedad institucional, pues estaba comprometida la posibilidad de funcionamiento de uno de los tres poderes que conformaban el Estado Argentino.

La acción iniciada por la Presidenta del Senado a la Corte Suprema, hizo recordar las preguntas remitidas en 1793 por Thomas Jefferson -cuando se desempeñaba como Secretario de Estado durante la primera presidencia de los Estados Unidos, a cargo de George Washington- a la Corte Suprema sobre la neutralidad norteamericana respecto de la guerra entre Francia e Inglaterra y la interpretación de ciertos tratados y leyes. Sin embargo, la Suprema Corte señaló que no podía dar respuesta a las preguntas formuladas, pues en caso de dar su opinión se violaría la separación de poderes ${ }^{43}$.

Creo que la Corte Suprema argentina a la hora de resolver tenía tres alternativas: 1 . Rechazar in limine la acción; 2. rechazar la acción pero, de todos modos, dejar sentada una postura a modo de obiter dictum; 3. admitir la acción y dar su opinión. La primera de ellas es la que desde el punto de vista de la técnica procesal correspondía, pues claramente no se configuraba el requisito de "caso" exigido desde antiguo por la Corte Suprema. La tercera de ellas, supondría romper de cuajo con una doctrina tradicional de la Corte Suprema, aunque para algunos constitucionalistas era lo más conveniente en términos de colaboración entre las ramas de gobierno, como referiré más adelante. El Máximo

\footnotetext{
43 En efecto, se ha señalado que la prohibición de que la Suprema Corte dé opiniones consultivas (“advisory opinions") está en el centro de la Sección III de la Constitución americana, que establece que los tribunales se expiden siempre que exista un caso (Chemerinsky, 2015: 90-98). En este sentido, cabe puntualizar que una jurisprudencia constante de la Corte Suprema ha definido el concepto de caso como aquellas causas "en las que se persigue en concreto la determinación del derecho debatido entre partes adversas" ("Administración de Parques Nacionales c/ Neuquén Provincia del s/ acción declarativa de inconstitucionalidad", 20/4/2010, Fallos: 333:487).
} 
Tribunal eligió la segunda postura. Rechazó la acción y, al mismo tiempo, afirmó que el Senado de la Nación "tenía todas las atribuciones constitucionales para interpretar su propio reglamento en cuanto a la manera virtual o remota de sesionar, sin recurrir a la Corte Suprema de Justicia de la Nación".

Considero que no es errada la postura adoptada por la Corte, pues señaló que no había caso pero, al mismo tiempo, y en atención a las especiales circunstancias que se están atravesando, dio su opinión al respecto "desde el punto de vista constitucional" -como ella expresó- dejando en claro que el Congreso no podía desatenderse de sus funciones esenciales. En efecto, precisó que la continuidad de la tarea de legislar del Congreso de la Nación resulta absolutamente esencial para el normal desarrollo de la vida constitucional de la Argentina ${ }^{44}$. Así, manifestó que la parálisis causada por la pandemia "exige de las instituciones de la República el desarrollo de los mecanismos que sus autoridades consideren necesarios para asegurar la permanencia de sus tareas", reseñando de qué modo distintos congresos y parlamentos adoptaron diferentes formas para continuar con sus funciones y cumplir su rol constitucional ${ }^{45}$.

El ministro Rosatti fue un poco más allá. A la vez que puntualizó que la acción no era de competencia de la Corte por no configurarse un caso, de modo más patente hizo alusión a las "consideraciones colaborativas" entre las ramas de gobierno. En efecto, adujo que "el principio de colaboración entre los poderes del Estado, que se invoca frente a la inédita situación planteada por la proyección de la pandemia en la vida institucional del país, justifica que [la] Corte -sin invadir competencias ajenas y sin prejuzgar a futuro-formule algunas consideraciones adicionales, recordando cuales han sido sus criterios jurisprudenciales". Asimismo, puso de manifiesto que la gravedad institucional no estaba en la incertidumbre que generaba la posibilidad de que el Congreso sesionara por medios virtuales, y en atención a esa gravedad la Corte se expida, sino precisamente en el hecho que el Senado, al no sesionar, dificultaba el procedimiento de sanción de las leyes y el funcionamiento de la Cámara de Diputados ${ }^{46}$.

Por su parte, Rosenkrantz, adoptando el primer criterio apuntado, rechazó in limine la presentación. Para decidir de ese modo, recordó que la exigencia de un caso es una característica esencial de la estructura del Poder Judicial de la Nación y, como tal, de la división de poderes que establece la Constitución. De forma concordante, expresó que la doctrina de la gravedad institucional no podía ser jamás usada para deformar o eludir las exigencias a las que la intervención de la Corte está constitucionalmente supeditada ${ }^{47}$.

\footnotetext{
44 Considerando $8^{\circ}$.

45 Considerando $9^{\circ}$.

46 En efecto, expresó que "la gravedad de la situación no deviene de la hipotética discusión sobre una ley tributaria que no ha sido aún presentada en la Cámara, que -por mandato constitucional- debería ser impetrada en la Cámara de Diputados (artículo 52, Constitución Nacional) y que es, por tanto -al menos hasta el presente- de existencia conjetural, sino de la alegada falta de funcionamiento de una Cámara del Congreso.

Si una Cámara no sesiona no pueden sancionarse leyes de cualquier tipo, no solo las tributarias o cuyas materias no sean susceptibles de ser reguladas por Decreto de Necesidad y Urgencia. Por el contrario, no puede adoptarse ninguna ley formal. Si una Cámara no funciona dificulta o impide el funcionamiento de la otra (artículo 65 de la Constitución Nacional). Y no solo la sanción de leyes quedaría trunca, también la función de control sobre los otros dos poderes del Estado, que es una función esencial, en este caso, del H. Senado" (considerando $8^{\circ}$ ).

47 Ver especialmente considerandos $6^{\circ}$ y $7^{\circ}$

De todos modos, podría decir que estoy de acuerdo con lo expuesto por la Corte Suprema, en la medida en que afirmó algo razonable, que lo podríamos enunciar en los siguientes términos: "ante una situación de emergencia, lo importante es que el Congreso siga funcionando, no cómo, ni dónde" (desde ya, siempre que se asegure un adecuado procedimiento). Pero ¿qué hubiese pasado, si la Corte, ateniéndose a un criterio "formalista irracional" -como denomina Gargarella (2020)- "colaboraba" afirmando que no serían válidas las formas virtuales de sesión del Congreso? En ese caso, se podría pensar que sería mejor que la Corte no complique la cuestión, guarde silencio, y solo se expida en casos concretos. Esta segunda cuestión, hace reflexionar, en definitiva, que la decisión adoptada por la disidencia parcial tampoco es errada.
} 
Es interesante destacar la visión de Gargarella (2020) sobre la cuestión, pues difiere de la mayoría de la doctrina que destaca que claramente la Corte no era competente para expedirse sobre la cuestión. El autor apunta que si bien era innecesaria, no era incorrecto que la Corte se pronuncie. Sobre la primera cuestión, la necesidad del inicio de la acción, el autor contrapone el constitucionalismo democrático y lo que llama "formalismo irracional", que designa a la postura que se inclina por el sometimiento del derecho a las formas aun cuando, por situaciones excepcionales, tales formas amenacen con socavar o quebrantar los principios sustantivos a los que dichas formas venían a servir. Para graficar la cuestión, pone el ejemplo de que el Congreso fuera bombardeado por un ejército enemigo, y se viera por tanto obligado a funcionar fuera de su lugar habitual, o forzado a saltear alguna práctica tradicional. Afirma que sería ridículo e irresponsable impugnar los esfuerzos que haga el Congreso para -a pesar de la tragedia- seguir deliberando, de un modo respetuoso de los principios democráticos que dan sentido a su accionar. En cuanto a la segunda cuestión, sobre si la Corte debía expedirse o no, se expresa de modo afirmativo. Su opinión se asienta en que su concepción democracia se asienta en el "diálogo" o la "conversación" colectiva, que incluye que se lleve a cabo entre las distintas ramas de poder. Precisa que esa "conversación" debe ponerse al servicio de la imparcialidad de las decisiones, apoyándose en la ayuda mutua y la cooperación entre las distintas ramas del poder.

Dejando de lado las cuestiones suscitadas en el precedente mencionado, cabe advertir que en las últimas décadas, el Poder Legislativo ha dejado el protagonismo en la producción normativa para combatir emergencias económicas y sociales al Poder Ejecutivo. Así, las medidas adoptadas no han sido leyes formales, con la debida publicidad y deliberación que acompañan estas normas, sino delegaciones o decretos de necesidad y urgencia (Ylarri, 2019b). De este modo, creo que a pesar de los recaudos que hay que adoptar para evitar la propagación del virus, el Poder Legislativo debe tener un rol preponderante en la toma de decisiones. Su accionar no debe limitarse al control que le compete sobre los decretos de necesidad y urgencia, conforme lo establece la ley 26.122, sino también en la deliberación de medidas a adoptar para solucionar las crisis en que nuestro país se encuentra sumergido hace casi un siglo.

Es por ello que las soluciones a la pandemia no deben esperarse de las buenas decisiones que pueda a llegar a encontrar un Presidente, sino institucional, pues, aun en emergencia, debe prevalecer un gobierno de leyes y no de hombres ${ }^{48}$. La forma más efectiva de combatir la pandemia no se limita a aumentar la discrecionalidad del Ejecutivo, sino en respetar los procedimientos establecidos constitucionalmente. Holmes (2004: 303304) hace una comparación muy clara respecto de las decisiones adoptadas durante emergencias con los protocolos que siguen los médicos en situaciones de emergencia. Pone de relieve que estos últimos, aun cuando una vida está en juego, siguen estrictos protocolos de cómo actuar, que lleva tiempo su aplicación, pero evitan caer en equivocaciones. Del mismo modo, destaca la importancia de que aun en emergencia existan reglas y procedimientos claros, pues las reglas no funcionan siempre y exclusivamente como restricciones que inhabilitan, sino que pueden servir como pautas estables, que permiten enfocarse en el propósito, recordar los objetivos a largo plazo y los peligros colaterales que de otro modo podrían pasar desapercibidos en una crisis urgente. 


\section{El adecuado control judicial}

Así como es de suma relevancia institucional que el Congreso ejerza las funciones que constitucionalmente tiene asignadas, es muy importante el adecuado control judicial sobre las medidas que se están adoptando.

Sobre la cuestión, me remito a lo expuesto en otro trabajo (Ylarri, 2020). Ahora bien, ¿qué han dicho los tribunales sobre las medidas adoptadas? Sobre la medida de aislamiento, un tribunal de apelaciones ha desestimado una acción de habeas corpus colectivo por medio del cual se requería la declaración de inconstitucionalidad del "aislamiento social, preventivo y obligatorio". En la sentencia, se determinó que el medio utilizado y las restricciones dispuestas que limitan la posibilidad de reunirse y circular fueron dispuestas también en forma razonable, teniendo en cuenta que era el único medio que la comunidad internacional y la información médica daba cuenta para evitar la propagación de la grave enfermedad. En cuanto a la proporcionalidad de la medida, indicó que también se ajustaba a los parámetros constitucionales en tanto se habían previsto supuestos que permiten la circulación de personas con tareas esenciales para sustento en cuestiones de necesidades alimentarias, de limpieza y médicas en lugares cercanos ${ }^{49}$. A su vez, el Poder Judicial admitió otras excepciones al aislamiento no previstas, como por ejemplo, para un niño con autismo severo que precisaba realizar una caminata diaria fuera de su residencia ${ }^{50}$.

También, se declaró constitucional el impedimento de reingreso de nacionales argentinos varados en el exterior ${ }^{51}$, criterio que no comparto. Pues no se discute qué el Estado asegure su retorno, sino que aun llegando al país por sus propios medios se le impida el ingreso ${ }^{52}$. Ello, sin perjuicio que, una vez en el país, el Estado lo obligue a adoptar medidas para evitar posibles contagios.

Por otro lado, se ha generado una gran polémica en torno a la determinación de la prisión domiciliaria de los detenidos. La Cámara Contencioso Administrativo Federal desestimó habilitar la feria para tratar una acción de amparo destinada a solicitar la prisión domiciliaria de las personas privadas de la libertad que se encuentren en situación de riesgo por el coronavirus Covid-19, pues la cuestión podía tener adecuado tratamiento por los tribunales orales penales ${ }^{53}$. En algunos casos, en atención al estado de salud del detenido, se admitió la prisión domiciliaria ${ }^{54}$. En otros casos, se rechazó dicha pretensión ${ }^{55}$, y se desestimó otorgar la excarcelación ${ }^{56}$.

Las normas mencionadas tienen también incidencia en las relaciones de familia. Un tribunal declaró la constitucionalidad de la prohibición de traslado del hijo de padres

\footnotetext{
49 Cámara Nacional en lo Criminal y Correccional, "Kingston, Patricio s/ Habeas corpus", Causa No 19.200/2020, 21/3/2020.

50 Juzgado de Primera Instancia en lo Contencioso Administrativo y Tributario $\mathrm{N}^{\circ} 10$ de la Ciudad de Buenos Aires, "Asesoria Tutelar CAyT No 2 c/ GCBA s/ Medida cautelar autónoma", 22/3/2020.

51 Cámara Federal de Apelaciones de Tucumán, “C., J. A. c/ Estado Nacional - Presidencia de la Nación y Otro s/ amparo ley 16.986”, 11/4/2020.

52 En este sentido, puede mencionarse que la Suprema Corte norteamericana ha señalado que quien goza de la ciudadanía, tiene derecho a la plena protección del Estado y el derecho absoluto de ingresar dentro de sus fronteras (“Tuan Anh Nguyen v. INS”, 2001, 533 U.S. 53, en p. 67).

53 Cámara Nacional de Apelaciones en lo Contencioso Administrativo Federal, Sala de feria, “D., C. J. c/ EN - PJN s/ Amparo Ley 16.986”, 11/4/2020.

54 Tribunal Oral en lo Criminal Federal Nº 2 de Córdoba, "I., M. A. s/ Condena", 17/3/2020; Tribunal Oral en lo Criminal Federal de Tierra del Fuego, Antártida e Islas del Atlántico Sur, “C., J. P. s/ Incidente de prisión domiciliaria”, 17/3/2020.

55 Tribunal Oral en lo Criminal Federal Nº 1 de Córdoba, “Anton, Mirta Graciela s/ Legajo de Ejecución Penal”, 19/3/2020.

56 Tribunal Oral en lo Criminal Federal Nro. 4 de San Martín, "Marcelo Cinto Courtaux", 18/3/2020.
} 
separados ${ }^{57}$. Sin embargo, con posterioridad, otro tribunal declaró inconstitucional la resolución del Ministerio de Desarrollo Social que autorizaba un único traslado de niños en los casos de quienes se encontraban en un domicilio diferente al dictarse la medida de aislamiento, fijándose un régimen de comunicación ${ }^{58}$. Poco tiempo después, la Jefatura de Gabinete de Ministros admitió el traslado de niñas, niños y adolescentes una vez por semana ${ }^{59}$.

Asimismo, es importante destacar a este respecto la declaración 1/20 de la Corte Interamericana de Derecho Humanos, que recordó las condiciones de validez de las restricciones que se establecen para combatir la pandemia. Señaló que las medidas que los Estados adopten, que puedan afectar o restringir el goce y ejercicio de derechos humanos, deben ser limitadas temporalmente, legales, ajustadas a los objetivos definidos conforme a criterios científicos, razonables, estrictamente necesarias y proporcionales, y acordes con los demás requisitos desarrollados en el derecho interamericano de los derechos humanos.

En otro orden de ideas, es constitucionalmente cuestionable el decreto 457/20 que suspendió durante el ejercicio 2020 la aplicación de los límites a las reestructuraciones presupuestarias que puede disponer el Jefe de Gabinete de Ministros -en función de lo establecido en el art. 37 de la ley 24.156, sustituido por la ley 26.124- para aquellas modificaciones presupuestarias necesarias en virtud de medidas dictadas en el marco del decreto $260 / 20$. Ténganse en cuenta que la doctrina ya se había expresado en contra de la constitucionalidad de la ley 26.124, que había admitido que el Jefe de Gabinete de Ministros pueda disponer reestructuraciones presupuestarias, las cuales no podrían superar cierto porcentaje del presupuesto (Badeni, 2015; Hernández, 2015; Luqui, 2015; Vanossi, $2015)^{60}$. Para enfrentar la pandemia, no sólo no se estableció algún límite porcentual más alto que el contemplado en el texto del art. 37 de la ley 24.156, sino que fuera de todo marco en el que se pueda ejercer dicha facultad, se suspendieron aquellos límites. Además, la cuestión fue adoptada por un decreto de necesidad y urgencia, cuando es el Congreso a quien le corresponde fijar el presupuesto, de conformidad a lo estipulado por el art. 75 , inc. $8^{\circ}$ de la Constitución Nacional.

En cuanto a las medidas de vigilancia digital a las que antes hice referencia, el tribunal interamericano puntualizó que deben disponerse las medidas adecuadas para que el uso de tecnología de vigilancia para monitorear y rastrear la propagación del Covid-19 sea limitado y proporcional a las necesidades sanitarias y no implique una injerencia desmedida y lesiva para la privacidad, la protección de datos personales, y a la observancia del principio general de no discriminación. Sobre la cuestión, Lorenzetti (2020a) sostiene que si bien estas herramientas, son muy efectivas y podrían ser adecuadas en esta crisis sanitaria, es dramáticamente peligroso si perduran en el tiempo y sin control, porque podrían ser el instrumento de un autoritarismo nunca visto.

Sin perjuicio de lo expuesto, cabe indicar que en épocas de emergencia los tribunales

\footnotetext{
57 Juzgado de Familia No 4 de San Isidro, “L. A. H.E. c/ S. M., S. s/ medidas protectorias”, 19/3/2020.

58 Juzgado Nacional de Primera Instancia en lo Civil N ${ }^{\circ} 23$, sentencia del mes de abril de 2020.

59 Decisión administrativa 703/2020 (B.O. 2/5/2020).

60 Si bien se inició una acción tendiente a impugnar la norma, la Corte Suprema desestimó el recurso extraordinario interpuesto contra la sentencia que había rechazado un amparo tendiente a que se declare la inconstitucionalidad del art. $1^{\circ}$ de la ley 26.124 , por entender que no se configuraba el requisito de "caso" ("Asociación por los Derechos Civiles (ADC) c/ Estado Nacional - ley 26.124 (DECI 495/06) s/ amparo ley 16.986", 3/8/2010, Fallos: 333:1212).
} 
han tendido a ser muy deferentes, y convalidar las normas adoptadas por los poderes públicos. Sobre el abuso del poder de policía y el escaso control judicial, Nino (2005: 493) señalaba que el poder reglamentario que concede el art. 14 -cuando dice que todos los habitantes gozan de ciertos derechos conforme a las leyes que reglamenten su ejercicio- "ha sido usado con considerable ligereza por los órganos políticos, contando con la consabida condescendencia de los tribunales". En la misma línea, se ha destacado que la emergencia económica en particular altera los roles institucionales: “Está hecha para el Ejecutivo, porque es el único que llega a tiempo. El Legislativo la refrenda. El Judicial, alguna vez, la corrige en sus efectos" (Frías, 1992). De igual modo, en el derecho norteamericano, se ha descripto la deferencia de los jueces ante las situaciones de emergencia de este modo: "cuando una emergencia tiene lugar, el Ejecutivo actúa, el Congreso consiente, y los tribunales son deferentes. Cuando la emergencia entra en decadencia, los jueces se vuelven más audaces y la búsqueda del alma comienza" (Posner y Vermeule, 2007: 3).

\section{Conclusiones}

A nivel mundial el Covid-19 ha generado una crisis sanitaria sin precedentes, con drásticas secuelas económicas y sociales también. Nuestro país no ha sido la excepción. Como señalé, la emergencia tiene dos consecuencias muy importantes: por un lado, origina una restricción a las libertades, derechos y garantías individuales; por el otro, acrecientan ciertas competencias del poder, reforzando algún órgano de gobierno, en particular el Poder Ejecutivo. ¿Esto significa que ante una situación de emergencia, debemos dejar la Constitución a un lado porque sus prescripciones no sirven para combatir situaciones excepcionales? En la práctica, justamente ha sucedido esto. La separación de poderes desaparece: el Poder Ejecutivo adopta prácticamente todas las decisiones, el Congreso permanece inmóvil ante aquéllas, y el Judicial simplemente convalida las medidas. Asimismo, la restricción de los derechos individuales es sumamente intensa y, lejos de ser una situación temporal, sujeta a un breve plazo, permanece vigente por mucho tiempo. Ese grito sagrado que cantamos en el himno de ¡libertad! jlibertad! jlibertad! pareciera haberse cambiado por el grito desgarrador de ¡emergencia! jemergencia! jemergencia!

Cabe entonces recordar un antiguo precedente de la Corte, en el que se expresa que "la Constitución es un estatuto para regular y garantir las relaciones y los derechos de los hombres que viven en la República tanto en tiempo de paz como en tiempo de guerra y sus provisiones no podrían suspenderse en ninguna de las grandes emergencias de carácter financiero o de otro orden en que los gobiernos pudieran encontrarse. La sanción de una ley, aun de emergencia, presupone, pues, el sometimiento de la misma a la Constitución"61. A su vez, como señala Hutchinson (2002: 340-344), emergencias -de tipo económico- ya podían leerse en las Actas de la Convención Constituyente de 1853. Sin perjuicio de ello, resalta que no se previó una solución especial ante esa situación, por lo que hoy día deberíamos manejarnos dentro del parámetro que ella fija. Esto nos debe llevar a reflexionar una vez más y buscar las soluciones a las crisis en la Constitución y no enseguida apartarnos de ella.

A finales del año 2019, el Congreso sancionó la ley 27.541 que declaró la emergencia en materia económica, financiera, fiscal, administrativa, previsional, tarifaria, energética, sanitaria y social, y delegó numerosas facultades al Ejecutivo. Pocas semanas después, sobrevino la crisis del Coronavirus y se dictaron numerosos decretos de necesidad y ur- 
gencia para atender la emergencia sanitaria y las consecuencias económicas y sociales. Pareciera que el país estaba hospitalizado y ahora ha pasado a terapia intensiva. Creo que está última situación excepcional generada por la pandemia permite poner de manifiesto lo que realmente es una situación de emergencia, y que los poderes públicos en muchas ocasiones dictan normas de emergencia cuando, si bien pueden haber ciertas dificultades o coyunturas problemáticas, éstas no son suficientemente graves para acudir a los poderes de excepción. En efecto, no caben dudas de la excepcionalidad que estamos viviendo. Pero es deseable que pronto se vuelva a la normalidad constitucional, y que la suspensión de ciertos derechos constitucionales dure el tiempo estrictamente necesario. Hay que recordar que el estado de emergencia "no es un cheque en blanco para el Presidente"62. De este modo, las medidas más restrictivas de los derechos individuales deben limitarse a ser "acciones quirúrgicas de emergencia" y no "tratamientos continuados preventivos y de acompañamiento"63.

La Argentina ha estado sumida en situaciones de emergencias y normas de emergencias durante prácticamente un siglo. Una nueva crisis realmente excepcional ha sobrevenido. Hay muchos problemas por resolver. Es deseable que se salga adelante con las instituciones y no con la discrecionalidad descontrolada del Ejecutivo. Es de absoluta importancia que el Congreso retome las facultades que tiene constitucionalmente asignadas. Que a través de la discusión y la deliberación pública se adopten soluciones de largo plazo a las emergencias endémicas en que estamos sumidos. Pues, la realidad lo indica, el ejercicio de facultades excepcionales en el Ejecutivo ha conducido sólo al deterioro institucional, a una permanente e intensa restricción de derechos individuales, y a una creciente pobreza e indigencia no sólo económica, sino también contraria a la dignidad humana.

\section{REFERENCIAS BIBLIOGRÁFICAS}

- Badeni, G. (2015). Palabras de apertura del acto. La Ley Online, La Ley, AR/DOC/1958/2015.

- Bidart Campos, G. J. (2000). Manual de la Constitución Reformada, t. II. Buenos Aires: Ediar.

- Bidart Campos, G. J. (1995). Tratado Elemental de Derecho Constitucional Argentino, t. I. Buenos Aires: Ediar.

- Boico, R.J. (2020). Constitución, coronavirus y aislamiento obligatorio. La Ley, 6/4/2020, 1-2.

- Cafferatta, N. A. (2020). Pandemia de coronavirus. Rubinzal Online, Rubinzal Culzoni, Doctrina, 1539/2020.

- Cao, C.A. (2020). ¿Estado de sitio? No por el momento. Ámbito, 19/3/2020. Disponible en: https://www.ambito.com/opiniones/coronavirus/estado-sitio-no-el-momento-n5089770. - Castro Videla, S. y Maqueda, S. (2020). La Ley de Abastecimiento y su aplicación descentralizada. Rubinzal Online, Rubinzal Culzoni, Doctrina, 1603/2020.

- Chemerinsky, E. (2015). Constitutional Constitutional Law. Principles and Policies. $5^{\circ}$ ed. New York: Wolters Kluwer.

- Cruz Villalón, P. (1984). Estados excepcionales y suspensión de garantías. Madrid: Tecnos.

- Dalla Vía, A. R. (2002a). El problema de la naturaleza jurídica de la emergencia. Revista Argentina del Régimen de la Administración Pública. Vol. 283, 37-45.

62 Suprema Corte de Estados Unidos, "Hamdi v. Rumsfeld”, 2004, 542 U.S. 507.

63 Sentencia del Tribunal Constitucional español, 68/2007, de 28 de marzo, Fundamento Jurídico 10. 
- De Otto, I. (1988). Derecho Constitucional. Sistema de Fuentes, $2^{\circ}$ ed. Barcelona: Ariel.

- Diana, N. (2020). Algunas reflexiones sobre la emergencia. La Ley Online, La Ley, AR/ DOC/332/2020.

- Frías, P. J. (1992). ¿Separación de poderes o qué?. La Ley, 3/11/1992, 1-3.

- Gargarella, R. (2020). La "consulta" del Senado a la Corte, y el diálogo entre poderes. seminariogargarella.blogspot.com [blog]. 23/4/2020. Disponible en: http://seminariogargarella.blogspot.com/2020/04/la-consulta-del-senado-la-corte-y-el.html.

- Gelli, M. A. (2008). Constitución de la Nación argentina. Comentada y concordada, $4^{\circ}$ ed., Buenos Aires: La Ley.

- Gross, O. y Ní Aoláin, F. (2006). Law in times of crisis: emergency powers in theory and practice. Cambridge: Cambridge University Press.

- Hernández, A. M. (2020a). La emergencia por el Covid-19 en Argentina. En: González Martín N. y Valadés D. (coords.), Emergencia Sanitaria por Covid-19. México: UNAM, 24-32. Disponible en: https://www.juridicas.unam.mx/publicaciones/detalle-publicacion/157.

- Hernández, A. M. (2020b). Emergencia, orden constitucional y covid-19 en Argentina. Constitución y Emergencia Sanitaria, Suplemento Especial de la Revista Digital de la Asociación Argentina de Derecho Constitucional, № 1, abril 2020. Disponible en: http:// aadconst.org.ar/revistadigital/revista/es-1/.

- Hernández, A. M. (2015). Hiperpresidencialismo y presupuesto. La Ley, 2015-F-705.

- Hernández, A. M. (2004). Las emergencias y la afectación del orden constitucional y de los derechos. En: VV.AA., Derecho constitucional. Buenos Aires: Universidad.

- Holmes, S. (2004). In Case of Emergency: Misunderstanding Tradeoffs in the War on Terror. California Law Review, vol. 97, N², 301-355.

- Hutchinson, T. (2002). La actual crisis y su solución desde el derecho. Revista de Derecho Público, vol. 2002-2, 337-368.

- Ibarlucía, E. (2020). Pandemia y Constitución. Constitución y Emergencia Sanitaria, Suplemento Especial de la Revista Digital de la Asociación Argentina de Derecho Constitucional, N 1, abril 2020. Disponible en: http://aadconst.org.ar/revistadigital/revista/es-1/.

- Jakab, A. (2006). German Constitutional Law and Doctrine on State of Emergency - Paradigms and Dilemmas of a Traditional (Continental) Discourse. German Law Journal, vol. $7, N^{\circ} 5,453-477$.

- Loianno, A. (2005). Estado de sitio y derechos humanos: la excepcionalidad de la emergencia. En Sabsay, D. A. (dir.), Colección de Análisis Jurisprudencial Derecho Constitucional. Buenos Aires: La Ley, Buenos Aires, 609.

- Lorenzetti, R. L. (2020a). La pandemia y el Estado de Derecho. Clarín, 27/3/2020. Disponible en: https://www.clarin.com/opinion/pandemia-derecho_0_Cn2vdqRV9.html.

- Lorenzetti, R. L. (2020b). El nuevo control social. Clarín, 11/3/2020. Disponible en: https:// www.clarin.com/opinion/nuevo-control-social_0_YWwS5TSc.html.

- Luqui, R. E. (2015). El equilibrio del presupuesto. La Ley Online. La Ley. AR/DOC/1960/2015.

- Marchiaro, E. J. (2020). Bloqueos municipales ante la pandemia. Rubinzal Online, Rubinzal Culzoni, Doctrina, 1560/2020.

- Mazzinghi, M. (2020). Congelamiento de cuotas de créditos, alquileres y suspensión de ejecuciones por la emergencia. La Ley, 14/4/2020, 19-20.

- Medina, G. y Yuba, G. (2020). Derecho comparado y coronavirus. La Ley, 13/4/2020, 5-8.

- Nino, C. S. (2005). Fundamentos de Derecho Constitucional. Buenos Aires: Astrea.

- Padilla, M. M. (2002). El control judicial de las declaraciones de emergencia. Revista Argentina del Régimen de la Administración Publica, vol. 283, 31-35.

- Posner, E. A. y Vermeule, A. (2007). Terror in the balance: security, liberty, and the courts. Oxford: Oxford University Press. 
- Ramírez Calvo, R. (2020). Constitución y emergencia. A propósito del Covid-19. Endisidencia.com [blog], 22/3/2020. Disponible en: http://endisidencia.com/2020/03/constitucion-y-emergencia-a-proposito-del-covid-19/.

- Sabsay, D. (2020). El Poder Legislativo debe seguir funcionando. La Nación, 9/4/2020. Disponible en https://www.lanacion.com.ar/opinion/columnistas/el-poder-legislativodebe-seguir-funcionando-nid2352468.

- Sacristán, E. B. (2014). Control judicial del estado de sitio y de la intervención federal. Revista de Investigações Constitucionais, vol. 1, N 1, 39-66.

- Sagüés, N. P. (2020). Mayores de 70: un pedido de autorización que nació mal y terminó diluido. La Nación, 22/4/2020. Disponible en: https://www.lanacion.com.ar/opinion/ mayores-70-pedido-autorizacion-nacio-mal-termino-nid2357002.

- Sagüés, N. P. (2019). Prologo. En: Ylarri, J. S. (2019). La emergencia económica. El control de constitucionalidad de la situación de emergencia económica y su declaración normativa. Ciudad de Buenos Aires: Ábaco.

- Schurig, H. (2020). Emergencia sanitaria, finanzas públicas y tributación Carta de Noticias, Procuración General de la Ciudad de Buenos Aires, Año 8, N 78, 18/4/2020, 68-71.

- Snowden, F. M. (2019). Epidemics and Society. From the Black Death to the Present. New Haven and London: Yale University Press.

- Vanossi, J. R. (2015). La desconstitucionalización del presupuesto nacional. La Ley Online, La Ley, AR/DOC/1963/2015.

- Vítolo, A. M. (2020). "Coronavirus: un nuevo paradigma jurídico-político", La Nación, 13/4/2020. Disponible en: https://www.lanacion.com.ar/opinion/columnistas/coronavirus-un-nuevo-paradigma-juridico-politico-nid2353550.

- Ylarri, J. S. (2020). Los alcances del control judicial sobre las normas adoptadas para enfrentar el Coronavirus. En: Falke, I. (dir.), La Tutela de la Salud Pública. El Derecho Procesal en Épocas del Coronavirus. Buenos Aires: IJ Editores.

- Ylarri, J. S. (2019a). Los decretos-leyes y el control de la "extraordinaria y urgente necesidad". Ciudad de Buenos Aires: Lajouane.

- Ylarri, J. S. (2019b). La emergencia económica. El control de constitucionalidad de la situación de emergencia económica y su declaración normativa. Ciudad de Buenos Aires: Ábaco. 